\title{
Evidence for physiological niche expansion of an intertidal flatworm: evolutionary rescue in the wild
}

Clayton, KA

http://hdl.handle.net/10026.1/16754

\subsection{4/meps 13473 \\ Marine Ecology Progress Series \\ Inter-Research Science Center}

All content in PEARL is protected by copyright law. Author manuscripts are made available in accordance with publisher policies. Please cite only the published version using the details provided on the item record or document. In the absence of an open licence (e.g. Creative Commons), permissions for further reuse of content should be sought from the publisher or author. 
1 Evidence for physiological niche expansion of an intertidal flatworm:

2 Evolutionary rescue in the wild

4 Katharine A. Clayton ${ }^{\star 1}$ and John I. Spicer ${ }^{1}$

$5{ }^{1}$ Marine Biology \& Ecology Research Centre, School of Biological and Marine Science,

6 University of Plymouth, Drake Circus, Plymouth, PL4 8AA, UK.

7

8 Running head: Physiological niche expansion

9

10 ACCEPTED MANUSCRIPT

*Katharine.96@outlook.com 
Microevolution may enable populations to adapt physiologically to rapid climate change. Where it exists, historical data could provide a rare opportunity to document such adaptation. The intertidal flatworm, Procerodes littoralis experiences large changes in salinity throughout the tidal cycle. We investigated whether regeneration performance of $P$. littoralis has changed over the last century. We repeated identical experiments to those published in 1914 on the same species, and from the same location. In the modern experiment, when tested across a range of different salinities $(\mathrm{S}=3,6,28,44$ and 53) $P$. littoralis could regenerate at lower salinities $(S=3)$ than reported previously. Also in the modern study, no significant optimum salinity could be identified, whereas in 1914 the optimum salinity $(S=28.5)$ was clear. The possibility of differences resulting from acclimation or oxygen availability instead of adaptation was investigated and discounted. It would appear, individuals from this population have extended their tolerance performance range further into hyposaline waters in the intervening 104 years since the previous study. Local climate change is suggested to be the microevolution driver, as mean daily precipitation has increased, and the number of days with no/trace precipitation per year has decreased in Plymouth, UK. Climate change is often considered a global phenomenon, but it drives local regime shifts. Here we suggest an evolutionary shift attributable to a century-long local change in precipitation.

Key Words: Microevolution, Specialism, Generalism, Historical, Niche expansion, Salinity, Climate Change 


\section{Introduction}

Adaptive evolution that prevents the extinction of a population is known as evolutionary rescue (Gomulkiewicz and Holt 1995) and may occur when a population faces rapid climate change (,Rice \& Emery 2003; Bell 2013, 2017). Piecing together the chronology of animal evolution and adaptation in the wild is becoming a growing area of research, especially as more evidence of adaptations are emerging, in the wake of extreme environmental pollution and climate change (e.g. Sanford \& Kelly 2011; Carlson et al. 2014,Bell 2017, Oziolor et al 2019). These studies primarily involve investigating local adaptations and where historical literature or museum specimens exists they can be an important resource, , to test for evolutionary rescue. For example, Higgins et al. (2014) repeated a 40 year old study on the thermal physiology of Colias spp. butterfly larvae suggested that their thermal physiology had shifted, and the shift was associated with climate change. The use of historical material in these instances, though currently quite rare, can provide a more refined adaptive evolution timeline for individual populations that are experiencing rapid environmental change, to establish whether or not evolutionary rescue takes place in the wild (Bell 2017 Mills et al. 2018).

At the beginning of the $20^{\text {th }}$ Century a series of carefully constructed and described experiments in which the wound-healing and regeneration performance over a range of environmental salinities of a small free-living flatworm from Wembury Bay, (Plymouth, UK) were carried out (Lloyd 1914). The object of those experiments was to 'discover how far marine turbellarians could be made to undergo variation while regenerating lost parts' (Lloyd 1914). Procerodes littoralis (Strom 1768) is a common intertidal planarian found where fresh water runs out over gravel and sand under loose rocks, in mid to upper shore intertidal streams where daily, it is subjected to 
1 both sea and fresh water ( $S=35$ - 0) (Hayward \& Ryland 2012, McAllen et al. 2002,

2 Pantin 1931). They only encounter freshwater during the low tide period as the sea retreats, and are submerged in sea water at high tide so it seems reasonable to assume that during a tidal cycle $P$. littoralis experiences acutely a range of salinities from fresh to full strength seawater depending on the tide height.

Regeneration is an evolved mechanism that mitigates the effects of damage by restoring functionality (Reichman 1984). It is well-known that planarians possess pronounced regeneration capabilities (e.g. Reddien \& Alvarado 2004). As soft bodied animals, planarians are susceptible to damage in the wild, which reduces functionality. The healing times of animals capable of regeneration provides a quantifiable proxy for fitness under different environmental conditions, allowing us to link Darwinian fitness with physiological performance (Kaack \& Pomory 2011).

Faithfully reproducing the study of Lloyd (1914) provides a rare opportunity to compare physiological performance in a marine animal roughly 50 years pre- and post- onset of the Anthropocene, an the Epoch which represents humans' influence on Earth, that arguably began around 1950 (Crutzen \& Steffen 2003, Steffen et al. 2007, Zalasiewicz et al. 2015). This might also provide an example of evolutionary rescue in the wild, if differences in performance can be linked with local environmental changes that have taken place over that same period of just over 100 years.

Anthropogenic climate change has caused increased precipitation since 1901 (medium confidence before and high after 1951) in the mid-latitudes of the Northern hemisphere (IPCC 2014). Concomitantly, the frequency and intensity of precipitation has likely increased in North America and Europe (IPCC 2014). Organisms are 
1 restricted to certain locations by a range of abiotic and biotic factors, salinity (osmotic pressure) being a key factor determining the distribution of aquatic species (Remane

\& Schlieper 1971). Consequently, marine organisms (particularly coastal and intertidal sessile and sedentary species) are subjected to a major physiological challenge when faced with increased precipitation, which in some organisms can be overcome (Lee \& Bell 1999). As this species lives at the interface between streams and sea water, individuals are likely to be directly influenced by such a hypothetical increasing freshwater input. This species is also a good model because it does not have a planktonic life stage so cannot migrate. Movement is further restricted by the fact that seaward the stream bed is unsuitable for this species as it becomes a wave cut platform with tidepools instead of loose rocks. Neither can they migrate upstream similar niche, e.g. Polycelis felina.

Based on these environmental data and observations, there is an opportunity to directly investigate potential physiological changes that have taken place approximately 50 years pre- and post- onset of the Anthropocene ( 1950).

Therefore, the aims of our study were two-fold: (1) To look for evidence of physiological differentiation over the past 100 years in a local, wild population in a species where we have good historical data on physiological performance. (2) To identify environmental change over the same period that might explain any detected physiological differences.

This was done by repeating the experiment presented in Lloyd 1914 faithfully, using regeneration (wound healing) time for $P$. littoralis (as Gunda ulvae in 1914) collected from the exact same location as a quantitative proxy for fitness under a wide range 
1 of salinity treatments and comparing their results with our own. The salinities range

2 ( $S=6-53)$, was chosen to represent the salinities that $P$. littoralis could experience tolerances for regeneration determined by Lloyd (1914). The rationale for including the lowest salinity $(S=3)$ is that Lloyd (1914) suggested that flatworms cannot heal at in such hyposaline water, and so including such a low salinity gives an opportunity to investigate whether they have shifted their tolerance over the past century. The rationale for using the higher salinity of $S=53$ is that the previous study suggested this was the species 'salinity extreme' and so we can test whether the species has either shifted or expanded the niche window of tolerance. Niche expansion is a key concept for physiology and ecology and has been studied in a wide range of taxa (e.g. Lancaster et al. 2015, Weng et al. 2005) and so this present study provides an excellent opportunity to broaden our knowledge by including poorly represented groups, such as the Platyhelminthes. As acclimation salinity was not recorded in the historic study method and because any difference detected between the historical and present day experiment could potentially be a result of plasticity, we carried out preliminary experiments to test for possible salinity acclimation plasticity in $P$. littoralis. When the salinity of sea water changes, so too does the oxygen concentration. And so, to test that what we termed a salinity effect in the core salinity tolerance experiment was not confounded by a potential hypoxic effect, the effect of reduced dissolved oxygen on regeneration time was investigated, keeping salinity and dissolved oxygen concentration constant.

Finally, a climatic link to the broadened salinity tolerance (particularly at low salinities) observed was suggested. As a consequence, local precipitation data were analysed to test the prediction that there has been an increase in the daily mean precipitation and a decrease in the number of days with no/trace precipitation per 
1 year in Plymouth, from 1931 until present, to marshal support for the hypothesis that

2 a broadened salinity tolerance evolved in response to increased freshwater exposure.

\section{Materials and methods}

6

7

\subsection{Collection and maintenance of flatworms}

Using a clean artists' paint brush, $P$. littoralis were collected from beneath rocks in the stream running down Wembury Bay, Devon, UK (50¹9'03.3”N 405'03.8'W) during Spring/Summer 2016 and Summer 2017. Flatworms were removed to the laboratory within $60 \mathrm{~min}$ of capture and kept in continuously aerated, dilute sea water $\left(S=22, T=15^{\circ} \mathrm{C}\right)$ for 7 days where they were distributed between a number of small aquaria (vol. = $8 \mathrm{~L}$ ). This salinity was chosen as it represents the mid-range salinity they experience in the wild (McAllen et al. 2002). During the holding period, flatworms were fed ad libitum on chopped defrosted cattle liver prior to a water change each day.

\subsection{Regeneration performance at different salinities}

To compare regeneration (wound healing) performance and tolerance over a range of different salinities the method presented in the previous study was followed as closely as possible (Lloyd 1914). Each $5 \mathrm{~mL}$ well in a 12-well plate was randomly assigned a treatment of either $S=3,6,28,44$ or 53 , identical salinities to those used in the previous study. The desired salinities were constructed by carefully mixing deionised water with natural sea water $(S=3,6$ and 28) or by dissolving Instant Ocean (Aquarium Systems) in natural sea water $(S=44$ and 53 ). Any loss due to 
1 evaporation was replaced by topping up with deionised water and the salinity

2 checked using a hand-held refractometer (Atago Master-One, Kyoto, Japan).

Individual flatworms ( $n>15$ per treatment) were starved for $3 \mathrm{~d}$ and then bisected along the transverse axis using a sharp scalpel blade, exactly as the previous study.

The anterior section of the individual was placed into separate treatment wells using a clean, fine paintbrush and posterior ends were discarded, the same as the previous study. To prevent the treated flatworms escaping, mesh $(0.5 \mathrm{~mm})$ was secured over the wells on the well plate and a lid was placed over the mesh to reduce evaporative water loss.

After the flatworms were bisected, the degree of regeneration of the posterior end of the anterior section from each individual was assessed visually every $24 \mathrm{~h}$ under low power magnification (EZ4, objective 8-35X, Leica Microsystems). Regeneration was defined as when no tissue protruded out of the bisected area and the wound was replaced with a smooth posterior, see Fig S1 for a photographic visual aid. Worms were not fed after being bisected in accordance with Lloyd 1914's methodology.

Water was replaced in each well every $24 \mathrm{~h}$. The experiment was carried out twice with a fresh batch of flatworms. There was no significant difference in wound healing time at the same salinity treatments between the first experiment and the repeat data sets (Kruskal-Wallis test; $P=0.961)$, and so data were pooled ( $n \leq 30$ per treatment) before analysis.

In the Lloyd 1914 study wound healing time was expressed as a range in days. We simulated the data from this range using a random number generator in $\mathrm{R}$ Studio corresponding to the same sample size employed in the current study. These generated data were subsequently used for statistical analysis. 
1 To formally test for any temporal difference (Loyd 1914 vs current study) in the

2 relationships between wound healing time and salinity, an estimation statistics approach (Ho et al., 2019) was adopted To quantify any differences detected

Gardner-Altman plots were generated using an open source website

(https://www.estimationstats.com/\#/analyze/two-independent-groups) The 95\%

bootstrap confidence intervals (bias-corrected and accelerated) were calculated from a nonparametric sampling of the data. P-values from two-sided permutation t-tests were also calculated and are reported alongside confidence intervals in the following format $($ mean difference $=x(95 \%$ confidence intervals—upper limit, lower limit $), p=$ ). For each permutation $\mathrm{P}$ value, 5000 reshuffles of the control and test labels were performed.

\subsection{Plasticity and salinity acclimation}

To test the possibility that the difference between the previous study (Lloyd 1914) and the present-day study could be accounted for by acclimation, and was therefore a result of plasticity, the following experiment was carried out. Flatworms $(n=12$ per treatment) from a stock aquarium $(S=22)$ were transferred to another aquarium and were kept at $\mathrm{S}=22$ or acclimated to 35 for $48 \mathrm{~h}$ before being used in the plasticity experiment described below. This acclimation period was relatively short because the flatworms experience large salinity fluctuations in the wild and so, it was assumed that they did not require a protracted period to adjust to changing ambient salinities.

Bisection, husbandry and wound healing determination were carried out exactly as described above (Sect.. 2.2), except that flatworms were kept at only one test salinity 
$1 \quad(S=53)$. The rationale behind the use of such high salinity was that it should,

2 potentially produce the most sensitive results compared to choosing a lower salinity that the worms may be more suited to. This is because of higher mortalities and longer healing times that were exhibited in the $S=53$ treatment compared to the $S=$ 3 treatment and it was important to ensure we included a salinity treatment that was used in the main experiment.

This experiment was conducted twice, the repeat experiment used flatworms collected from the same location but at a different time. There was no significant difference between the resultant data sets (Kruskal-Wallis test; $P=0.961$ ), so they were combined $(n=24)$. These data were treated as non-normally distributed following a Shapiro-Wilk test and the effect of salinity acclimation tested using the non-parametric Wilcoxon Rank Sum test with continuity correction.

\subsection{Regeneration after pre-acclimation to low oxygen tensions}

Here, the experiment described in section 2.2 was repeated using two extreme salinity treatments $S=3$ and 44 . Flatworms ( $n=8$ per treatment) from the stock aquaria (acclimated to $S=22, T=15^{\circ} \mathrm{C}$ ) were bisected along the transverse axis and the anterior section of the individual was placed using a clean, fine artist's paintbrush into separate air-tight glass jars to keep oxygen concentration as constant as possible (each vol. $=11 \mathrm{~mL}$ ) containing one of four experimental treatments: low salinity-normoxia, high salinity-normoxia, low salinity-hypoxia and high salinityhypoxia. Seawater solutions of different salinity were prepared exactly as described above. Normoxic conditions (nominally $\mathrm{O}_{2}=8 \mathrm{mg} \mathrm{L}^{-1}$ ) were created by gently aspirating the sea water solution in the jar with scrubbed atmospheric air supplied, via an air pump. Hypoxic conditions (nominally $\mathrm{O}_{2}=3 \mathrm{mg} \mathrm{L}^{-1}$ ) were produced by 
1 aspirating the sea water solution in the jar with a scrubbed air: nitrogen mix.

2 Regeneration time was determined exactly as described for the experiment outlined

in section 2.2. These data were treated as non-normally distributed and heterogenous according to the Shapiro-Wilk test and Levene's test, therefore any effects of hypoxia were tested for using the non-parametric Kruskal-Wallis test.

\subsection{Local precipitation data}

Daily precipitation data collected from the Mount Batten Weather Station, Plymouth, Devon, UK between 1931 and 2016 (except 1946, 1947 and 1948) were obtained from the Met Office National Meteorological Archive, Exeter. The mean daily rainfall from each year between 1931 and 2016 (except 1946-48 due to missing values, $n=$ 83) were determined non-seasonal after decomposing the data and a Holt-Winters exponential smoothing with trend and without seasonal component was performed. Raw data had less than $10 \%$ missing values and those missing values were repaired using the Seasonally Decomposed Missing Value Imputation function. A 15 year forecast of mean daily rainfall in Plymouth from the Holt-Winters filtering with a lag of 20 was produced. To ensure that these data met the assumptions of the HoltWinters model, further analyses were conducted and included: Pearson's correlation coefficient and a KPSS test for correlation and stationarity, an autocorrelation plot and Ljung Boxplot analyses to test for autocorrelation, a histogram of forecasted errors was produced and a Shapiro-Wilks test to identify normality and, a plot was produced to identify homogeneity in the variance of the residuals. Number of days with no/trace precipitation from each year between 1931 and 2016 (except 1946, 1947, 1948 and 1969) ( $n=82)$ were extracted and treated as normally distributed following a Shapiro-Wilk test and were tested for a correlation with time (year) using a Pearson's correlation coefficient. 


\section{$1 \quad 2.6$ Statistical analyses}

$2 \quad$ Non estimation statistics analyses were conducted in $\mathrm{R}$ (version 3.2.4.) using

3 RStudio (version 1.1.383 RStudioTeam, 2016). Non-parametric tests (Shapiro-Wilk

4 and Levene's Test) were used to ensure statistical uniformality between treatments

5 as some data had non-normal distribution and were heterogenous, even after being

6 transformed logarithmically and using square root transformation. The estimation

7 statistics were conducted using an open source website

8 (https://www.estimationstats.com/\#/analyze/two-independent-groups) (Ho et al.

9 2019)

\section{Results}

\subsection{Regeneration performance at different salinities}

While in the modern experiment flatworms healed in all treatments, including the lowest salinity used $(S=3)$, there was no healing at $S=3$ as reported in the previous study (Lloyd 1914) (Fig. 1A).

Mortality was greatest at the salinity extremes $(S=3$ and 53$)$ and decreased through to the mid salinity (Fig. 1B). All flatworms in $S=3,6$ and 28 either healed or died within $11 \mathrm{~d}$. At $S=44$ three individuals did not heal and at $S=53$ seven individuals did not heal within $11 \mathrm{~d}$.

Simulated data generated from the results presented in Lloyd (1914) indicated that there would have been significant differences across the salinity range examined. We detected a significant difference between the modern data and the historic (simulated) data at $\mathrm{S}=6$ (unpaired mean difference $=4.82 \mathrm{~d}(95 \% \mathrm{Cl} 4.14,5.29), P$ $<0.05), \mathrm{S}=28$ (unpaired mean difference $=-2.57 \mathrm{~d}(95 \% \mathrm{Cl}-3.47,-1.83), P<$ $0.05), S=44$ (unpaired mean difference $=1.74 \mathrm{~d}(95 . \% \mathrm{Cl} 0.474,2.58) P<0.05)$, 
1 but not at $\mathrm{S}=53$ (unpaired mean difference $=0.444 \mathrm{~d}(95 \% \mathrm{Cl}-1.56,1.56) P=$

$2 \quad$ 0.499) (Fig. 2).

3

4

\subsection{Salinity acclimation plasticity}

Flatworms exhibited no significant salinity acclimation plasticity under the conditions tested. There was no significant difference in regeneration times between differentially acclimated individuals ( $S=22$ and 35) (Wilcoxon Rank Sum test with continuity correction, $P=0.572)$. Wound healing took approximately $8 \mathrm{~d}$ in each case. However, an increase in mortality (10 more deaths) was recorded at $\mathrm{S}=22$ compared with $\mathrm{S}=35$ acclimated flatworms. The number of unhealed individuals by $11 \mathrm{~d}$ was two from $\mathrm{S}=22$-acclimated and four from $S=35$-acclimated flatworms.

\subsection{Wound healing performance and pre-acclimation to low oxygen tensions}

Dissolved oxygen concentration did not affect wound healing time of flatworms. There was no significant difference in wound healing time of flatworms exposed to hypoxia or normoxia at either salinities (Kruskal-Wallis test, $P=0.195$, Fig. 3). Mortality was low in all treatments, one death in $\mathrm{S}=3$ and $\mathrm{S}=44$ at $\mathrm{O}_{2}=3 \mathrm{mg} \mathrm{L}^{-1}$ in both cases.

\subsection{Precipitation in Plymouth since 1931}

The Holt-Winters Exponential smoothing with trend and without seasonal component model was generated with the following smoothing parameters and coefficients and the sum of squared errors was calculated. A forecast from the Holt-Winters 
1 smoothing model was predicted for 15 years into the future (Fig 4.) This suggests an overall upward trend in mean daily rainfall.

Mean daily precipitation in Plymouth showed a significant positive correlation with time between 1931 and 2016. The mean daily rainfall data was described as nonstationary with a trend following significant results from a KPSS test $(P=0.0361)$ and Pearson's correlation $\left(R^{2}(\operatorname{adj})=0.04663, P<0.05, n=83\right)$ (Fig 5.A). An autocorrelation plot was produced from the forecast and the residuals were touching the confidence interval line (0.2) and so a Ljung-Box Test was conducted to test for non-zero autocorrelation. This test was non-significant $(P>0.05)$ with a lag maximum of 20 and so there is little evidence of non-zero autocorrelations in the sample with forecast errors at lags 1-20 (Fig 5.B). A constant variance within the residuals was assumed (Fig 5.C). A histogram was then generated to visualise the forecast errors which suggests that the errors are roughly centred on zero but slightly skewed to the left. A Shapiro-Wilks test for normality was then conducted which was non-significant $(P>0.05)$ so the data can be considered normally distributed (Fig 5.D).

Number of days with no/trace precipitation in Plymouth showed a significant negative correlation with time between 1931 and 2016 (Pearson's correlation, $R^{2}(\operatorname{adj})=$ 0.2433, $P<0.005, n=82$ ) (Fig. 6).

\section{Discussion}

Since 1914, a key aspect of physiological performance, namely regeneration, in waters of different salinities of the Wembury Bay population of $P$. littoralis has broadened. Although we cannot fully discount the suggestion that methodological variations could still play a role in the results, we suggested that we have presented 
1 good evidence that these flatworms now perform and survive better in hyposaline

2 waters than they did over century ago. The lowest salinity limit for healing in 1914 was $S=5.7$ and currently is at least $S=3$ (Lloyd 1914). Furthermore, the Wembury population in 1914 displayed an optimum performance salinity of $\mathrm{S}=28.5$ (Lloyd 1914) whereas in our study, performance was better across a wider salinity range with no obvious optimum. Physiologically, this suggests that $P$. littoralis has adapted further into hyposaline waters whilst simultaneously maintained the ability to heal in hypersaline conditions. Therefore, we suggest that our study provides evidence that the population has experienced a microevolutionary niche expansion, shifting from specialism to generalism in terms of salinity tolerance performance, over approximately 100 years. In this study microevolution is defined as a change in a measurable trait in individuals of a population over a short time period. This conclusion is supported by the performance curve across the salinity treatments from this study fits a linear model (where there is a positive correlation between mean wound healing time and salinity). Lloyd's 1914 data do form a 'typical' environmental tolerance normal distribution curve, whereby performance is best in the mid-range of the salinities which tails off towards the extremes ( $S=3$ and 53). This change does not seem to be explained by acclimation, but is possibly attributable to environmental salinity change per se, rather than accompanying physico-chemical changes in oxygen solubility affecting oxygen availability.

Performance curves can be used to qualitatively model physiological tolerance against energy expenditure. Although commonly used to characterise thermal tolerances, performance curves provide a useful tool to visualise the response of an organism to environmental stress (Chown et al. 2010). The regeneration performance of $P$. littoralis at a range of salinities from the historical and modern 
1 study can be presented together (Fig. 4A). This visualisation is comparable to and supports the specialism versus generalism model proposed by (Huey \& Hertz 1984) (Fig. 4B). In this microevolutionary process, the population of $P$. littoralis has gained breadth and lost maximum performance in terms of salinity tolerance. During environmental change, specialism can be disadvantageous and a strategy associated with extinction (Colles et al. 2009, McKinney 1997). Whereas in thermal performance models, it has been suggested, that those with broader tolerance ranges (generalists) are favoured in variable environmental conditions (Gilchrist 1995). Therefore, we suggest that increasing salinity variability over 100 years due to increased precipitation in Plymouth along with usual tidal cycles, has favoured individuals with broader salinity tolerance ranges (generalists). According to the theory of evolutionary rescue (Gomulkiewicz \& Holt 1995), these generalists could potentially evolutionarily 'rescue' the Wembury Bay, Devon population of $P$. littoralis from the effects of the projected precipitation increase in the mid latitudes. This type of occurrence is rare but not unknown, as a shift in performance curves from a specialist curve to a generalist curve in 40 years, associated with climate change has also been documented previously in a terrestrial species (Higgins et al. 2014).

Evolutionary rescue in response to rapid climate change has been supported by studies of experimental evolution (Bell \& Gonzalez 2009), but models suggest that this may lead to overestimations of evolvability in wild, locally adapted populations (Schiffers et al. 2012). Transferring information from evolvability models and applying it to natural populations is challenging (Gomulkiewicz \& Shaw 2012). Caution is required when using evolutionary rescue in terms of this study, as factors other than healing time may influence fitness. 
1 An alternate interpretation of our data is that what we are witnessing is not niche expansion or evolutionary rescue of one species, but the consequences of speciation. While in the current experiment more individuals died at the salinity extremes, healing was quicker at $S=6$ compared with $S=28$. It could be suggested that two species are living in this habitat but occupy different salinities. One species could have exhibited greater healing performance at the higher salinities ( $S \geq 28$ ) and so, died more frequently at the lower salinities ( $S=3$ and 6$)$. The second species could have a greater healing performance at the lower salinities $(S \leq 28)$ and so, died more frequently at the higher salinities $(S=44$ and 53$)$. It is also worth noting that the mortality data follow a similar pattern to Lloyd 1914 healing time data, this adds to the evidence that a sub section of the population has diverged into hyposaline tolerance and the other has remained physiologically similar to the population from 1914. In Plymouth there could be a second congeneric species named Procerodes irenae (Hartog 1968). This suggestion received little support and it was concluded that the morphological differences observed were not enough to warrant both phenotypes being recognised as separate species (Ball \& Reynoldson 1981). That said, given the recent advancement in molecular techniques in phylogenetic analysis, and as generalists are favoured when faced with climate change, it may be interesting to revisit this 'two species' hypothesis.

It is important to recognise that repeating this experiment does introduce some variables that cannot be mitigated against. These include inconsistencies with the method, for example the mixture of salts used to make the high salinity seawater would be different as well as the water chemistry in the freshwater used to make the lower salinity treatment. The acclimation conditions could be different, but it is assumed this would not be the case due to the results from the acclimation plasticity 
1 experiment. In this experiment the flatworms were fed to ensure they all were starting from the same energy budget, but in Lloyd they were starved. It is not thought that this would have an effect on the results as the previous study states "When bisected, [the worms] restored their normal form as rapidly as did fully fed specimens" (Lloyd 1914). Simulating Lloyd's data could introduce bias but the difference observed is large enough that this would not cause a large enough effect.

The evolution of niche expansion has been shown to be attributed to biotic factors such as, intraspecific competition (Bolnick 2001) and predation (Seeley 1986) as well as abiotic factors such as, physical environmental shifts (Scott et al. 2003). A potential driver for the evolutionary shift reported in this study, could be a change in local precipitation. The average increase of daily precipitation in Plymouth since 1931 is in accordance with reports (IPCC 2014), that state that precipitation has increased in the mid-latitudes of the Northern hemisphere since 1901 (IPCC 2014). As previously stated, $P$. littoralis is directly at risk from increased freshwater input as this species has no planktonic life stage it is unlikely to be capable of migrating to another area. This increase in precipitation offers a potential explanation as to why $P$. littoralis has developed wound healing ability at $\mathrm{S}=3$ and improved healing performance at $S=6$. Maintaining an ability to heal at higher salinities is also important as warming also threatens mid-latitudes too (IPCC 2014). Increasing temperatures could cause coastal areas to experience increased salinities due to evaporation, and so the nature of this microevolutionary niche expansion buffers against increased precipitation and temperature.

$P$. littoralis has physiologically expanded into hyposaline waters and, now has potential to invade freshwater. In the past 200 years, this phenomenon has been 
1 facilitated by humans, usually by transplantation or habitat modification (Lee \& Bell

2 1999). To our knowledge, there is no evidence suggesting that marine planarians have invaded freshwater over a microevolutionary time frame. As cryptic species though, planarians may often be overlooked in terms of investigating freshwater invasions. $P$. littoralis is usually restricted to the stony substratum of the intertidal zone (Ball \& Reynoldson 1981). At Wembury Bay the stony substratum extends up to the fully freshwater stream, so in this case, substratum is not the limiting factor. The other restriction is, that $P$. littoralis cannot reproduce in freshwater, although it needs to be confirmed whether or not individuals from the Wembury Bay population can complete a life cycle in hyposaline water (Ball \& Reynoldson 1981). Finally, all triclad flatworms are carnivorous and niche competition between $P$. littoralis and the freshwater planarian Polycelis felina (found further upstream at Wembury Bay) may also be a barrier to this population of $P$. littoralis extending further upstream into freshwater.

To conclude, it is suggested that a microevolutionary niche expansion has occurred within the same population of $P$. littoralis over the past 100 years. Comparing historical findings with modern data provide an intermediate method between experimental evolution and palaeontological analysis of the fossil records to explore evolutionary physiology. The former may not be ecologically relevant (Carlson et al. 2014).The latter can be described as saltational or discontinuous evolution, lacking resolution to investigate transitionary periods in evolution on the scale presented in this study (Kirkpatrick 1982). But we can now start to utilise historic data more widely to better understand how organisms have changed and are changing in response to the Anthropocene. 
1 The experiments were conceived and planned by KAC and JIS, carried out by KAC, and the manuscript was produced by KAC and JIS.

$4 \quad$ We declare we have no competing interests.

\section{Funding}

6 The study was supported by the School of Biological \& Marine Sciences, University 7 of Plymouth.

\section{Acknowledgements}

9 We thank Ann Torr, Richard Ticehurst, Roger Haslam and Jo Triner for technical assistance, Emily Miles of the National Marine Biological Library at the Marine

Biological Association for information on Dorothy J. Lloyd, Andy Foggo, Davis Laundon and Daniel Montgomery for their contributions to our statistical analyses, the Met Office National Meteorological Archive, Exeter for access to historic weather detail and lastly the reviewers for their critical but constructive comments.

Ball IR, Reynoldson TB (1981) British planarians, Platyhelminthes, Tricladida : keys and notes for the identification of the species. Cambridge University Press, New York

Bell G, Gonzalez A (2009) Evolutionary rescue can prevent extinction following environmental change. Ecol Lett 12:942-948

Bell G, (2013) Evolutionary rescue and the limits of adaptation. Phil Trans R Soc B: Biol Sci 368: 20120080

Bell G, (2017) Evolutionary rescue. Annu Rev Ecol, Evol Syst, 48: 605-627

Bolnick DI (2001) Intraspecific competition favours niche width expansion in Drosophila melanogaster. Nature 410:463-466 
1 Carlson SM, Cunningham CJ, Westley PAH (2014) Evolutionary rescue in a

2 changing world. Trends Ecol Evol 29:521-530

3 Chown SL, Hoffmann AA, Kristensen TN, Angilletta MJ, Stenseth NC, Pertoldi C 4 (2010) Adapting to climate change: A perspective from evolutionary physiology. Clim 5 Res 43:3-15

6 Colles A, Liow LH, Prinzing A (2009) Are specialists at risk under environmental 7 change? Neoecological, paleoecological and phylogenetic approaches. Ecol Lett $8 \quad 12: 849-863$

9 Crutzen PJ, Steffen W (2003) How long have we been in the Anthropocene era? An 10 Editorial Comment. Clim Change 61:251-257

Gilchrist GW (1995) Specialists and Generalists in Changing Environments. I. Fitness Landscapes of Thermal Sensitivity. Am Nat 146:252-270

Gomulkiewicz R, Holt RD (1995) When does Evolution by Natural Selection Prevent Extinction? Evolution (N Y) 49:201

Gomulkiewicz R, Shaw RG (2012) Evolutionary rescue beyond the models. Philos Trans R Soc B Biol Sci 368:20120093-20120093Hartog C Den (1968) Marine Triclads from The Plymouth Area. J Mar Biol Assoc United Kingdom 48:209-223

Higgins JK, MacLean HJ, Buckley LB, Kingsolver JG (2014) Geographic differences and microevolutionary changes in thermal sensitivity of butterfly larvae in response to climate. Funct Ecol 28:982-989

Ho J, Tumkaya T, Aryal S, Choi H. and Claridge-Chang A. (2019). Moving beyond P values: data analysis with estimation graphics. Nat. Methods 16:565-566.

Huey RB, Hertz PE (1984) Is a Jack-of-All-Temperatures a Master of None?

Evolution (N Y) 38:441-444

IPCC 2014 Climate Change 2014: Synthesis Report. Contribution of Working Groups I, II and III to the Fifth Assessment Report of the Intergovernmental Panel on Climate Change (eds Pachauri RK, Reisinger A). IPCC, Geneva, Switzerland: IPCC

Kaack KE, Pomory CM (2011) Salinity effects on arm regeneration in Luidia clathrata (Echinodermata: Asteroidea). Mar Freshw Behav Physiol 44:359-374

Kerfoot WC, Weider LJ (2010) Experimental paleoecology (resurrection ecology): 
Lloyd D (1914) The Influence of osmotic pressure upon the Regeneration of Gunda ulvae. Proc R Soc London 88:1-20

McAllen R, Walker D, Taylor A (2002) The environmental effects of salinity and temperature on the oxygen consumption and total body osmolality of the marine $f$ latworm Procerodes littoralis. J Exp Mar Bio Ecol 268:103-113

McKinney ML (1997) Extinction vulnerability and selectivity: Combining ecological and paleontological Views. Annu Rev Ecol Syst 28:495-516

Mills LS, Bragina EV, Kumar AV, Zimova M, Lafferty DJ, Feltner J, Davis BM, Hackländer K, Alves PC, Good JM, Melo-Ferreira J (2018) Winter color polymorphisms identify global hot spots for evolutionary rescue from climate change. Science 359: 1033-1036

Pantin CFA (1931) The adaptation of Gunda ulvae to salinity III. The electrolyte exchange. J Exp Biol 8:82-94

Reddien PW, Alvarado AS (2004) Fundamentals of planarian regeneration. Annu Rev Cell Dev Biol 20:725-757

Reichman OJ (1984) Evolution of regeneration capabilities. Am Nat 123:752-763

Remane A, Schlieper C (1971) Biology of Brackish Water, 2nd edn. John Wiley \& Sons, Inc., New York

Rice KJ, Emery NC (2003) Managing microevolution: restoration in the face of global change. Front Ecol Evol 1:469-478

RStudioTeam (2016) RStudio: Integrated development environment for R.

Sanford E, Kelly MW (2011) Local adaptation in marine invertebrates. Ann Rev Mar Sci 3:509-35

Schiffers K, Bourne EC, Lavergne S, Thuiller W, Travis JMJ (2012) Limited evolutionary rescue of locally adapted populations facing climate change. Philos Trans R Soc B Biol Sci 368:20120083-20120083

Scott SN, Clegg SM, Blomberg SP, Kikkawa J, Owens IPF (2003) Morphological shifts in island-dwelling birds: The roles of generalist foraging and niche expansion. Evolution (N Y) 57:2147-2156

Seeley $\mathrm{RH}$ (1986) Intense natural selection caused a rapid morphological transition in a living marine snail. Proc Natl Acad Sci 83:6897-6901

Steffen W, Crutzen PJ, McNeill JR (2007) The Anthropocene: Are humans ow overwhelming the great forces of Nature. AMBIO A J Hum Environ 36:614-621

Strom H (1768) Beskrivelse over Norske Insecta. Kongl. Norske Videnske. Selsk. Skr. Trondheim IV:313-371

Weng KC, Castilho PC, Morrissette JM, Landeira-Fernandez AM, Holts DB, Schallert RJ, Goldman KJ, Block BA (2005) Satellite tagging and cardiac physiology reveal niche expansion in salmon sharks. Science (80- ) 310:104-106 
1 Zalasiewicz J, Waters CN, Williams M, Barnosky AD, Cearreta A, Crutzen P, Ellis E, 2 Ellis MA, Fairchild IJ, Grinevald J, Haff PK, Hajdas I, Leinfelder R, McNeill J, Odada 3 EO, Poirier C, Richter D, Steffen W, Summerhayes C, Syvitski JPM, Vidas D, 4 Wagreich M, Wing SL, Wolfe AP, An Z, Oreskes N (2015) When did the 5 Anthropocene begin? A mid-twentieth century boundary level is stratigraphically 6 optimal. Quat Int 383:196-203

\section{Figure Legends}

Fig. 1. Effect of different salinity treatments on the regeneration (wound healing) time (A) and mortality (B) of bisected Procerodes littoralis. A. Wound healing times from the modern study are displayed as grey bars. Simulated wound healing times taken from a range presented in Lloyd 1914 are displayed as black bars. Values are expressed as means \pm 1 S.E.

Fig. 2. The mean difference between the modern data and historic (simulated) data for $S=6,28,44$ and 53 is shown in this Gardner-Altman estimation plot. Both groups are plotted on the left axes; the mean difference is plotted on a floating axes on the right as a bootstrap sampling distribution. The mean difference is depicted as a dot; the $95 \%$ confidence interval is indicated by the ends of the vertical error bar (Ho et al. 2019).

Fig. 3. Effect of high $\left(\mathrm{O}_{2}=8 \mathrm{mg} \mathrm{L}^{-1}\right)$ and low $\left(\mathrm{O}_{2}=3 \mathrm{mg} \mathrm{L}^{-1}\right)$ dissolved oxygen on the regeneration time of Procerodes littoralis in $\mathrm{S}=3$ and $\mathrm{S}=44$ salinity treatments.

Values are expressed as means $\pm 1 \mathrm{~S} . \mathrm{E}\left(\mathrm{S}=3\right.$ at $3 \mathrm{mg} \mathrm{L}^{-1} n=7 ; \mathrm{S}=3$ at $8 \mathrm{mg} \mathrm{L}^{-1} n=8$; $\mathrm{S}=44$ at $3 \mathrm{mg} \mathrm{L}^{-1} n=7 ; \mathrm{S}=44$ at $8 \mathrm{mg} \mathrm{L}^{-1} n=8$ ). Note: there are no error bars on the $\mathrm{S}$ $38 \mathrm{mg} \mathrm{L}^{-1}$ bar because all individuals healed on the same day.

Figure 4. Mean daily rainfall data collected from Mount Batten, Plymouth (black line). Holt-Winters exponential smoothing of the mean (red line) and the forecast 15 year i 
1 nto the future (blue line). The dark blue shaded area represents the $80 \%$ prediction $\mathrm{i}$

2 nterval and the grey shaded area is the $95 \%$ prediction interval.

4 Figure 5. (A) Average daily precipitation $(\mathrm{mm})$ per year at Mount Batten, Plymouth, U $5 \quad \mathrm{~K}$ between 1931 and 2016. Line of best fit shows a significant positive relationship. (

$6 \mathrm{P}<0.05, \mathrm{n}=83)$. Data courtesy of the Met Office National Meteorological Archive, Exet 7 er.

9 Fig 6. Number of dry days (no precipitation/trace) per year at Mount Batten, Plymout h, UK between 1931 and 2016. Line of best fit shows a significant positive relationshi $p(P<0.005, n=82)$. Data courtesy of the Met Office National Meterological Archive, $E$ xeter.

Fig. 7. (A) Performance curves for regeneration ability of $P$. littoralis across a range o f salinities from Lloyd's 1914 study and from the present study. The present study val ues are a mean from each salinity treatment, Lloyd's performance curve is generated from medians from the ranges recorded in Lloyd's results. Performance indicates the inverse of wound healing time, the higher the performance the quicker the wound he aling time, where the curve meets the $\mathrm{x}$ axis this indicates that the worms cannot hea I at that salinity. (B) The specialism versus generalism model proposed by Huey and Hertz (1984).

Fig. S1 (A) A P. littoralis that has been bisected and is in the process of healing, note the protrusions at the posterior end which indicates an open wound. (B) The posterio r end of a $P$. littoralis that has been bisected and is now healed, B.1 highlights the s 
1 mooth posterior, this was at the point where individuals would be marked as healed.

2 Scale bars indicate approximately $1 \mathrm{~mm}$.

3 Fig. S2. (A) An autocorrelation plot of the forecasted residuals generated from the $\mathrm{H}$

4 olt Winters forecast, blue dashed line indicates the confidence interval line. B) Plotte

$5 \mathrm{~d}$ residuals of the mean daily rainfall data that have been detrended showing a rough

6 constant (homogenous) variance. (C) A histogram of forecasted errors from the Holt-

7 Winters model indicating a normal spread around zero with a slight skew to the left.

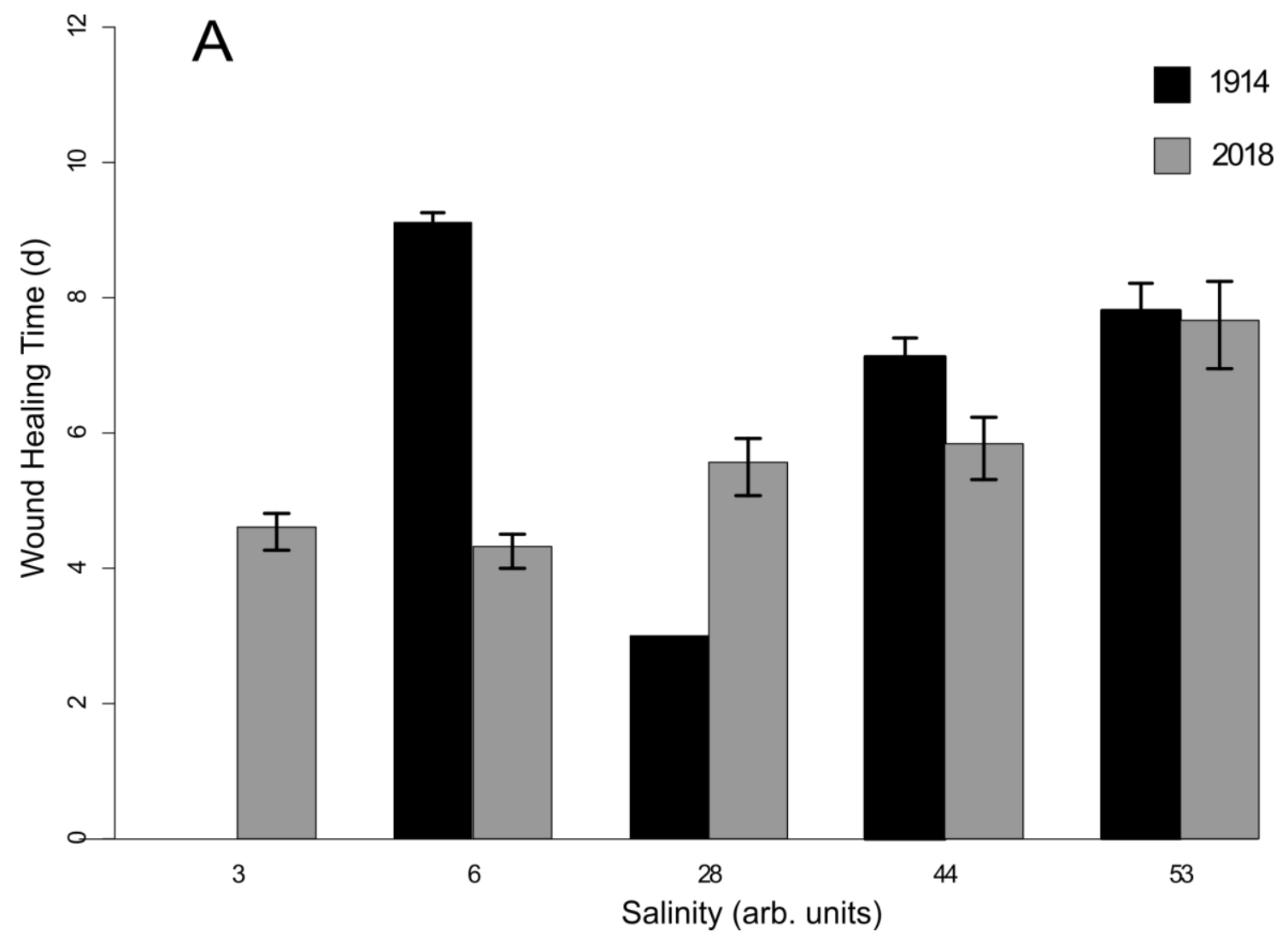


Physiological niche expansion

1

2

3

4

5

6

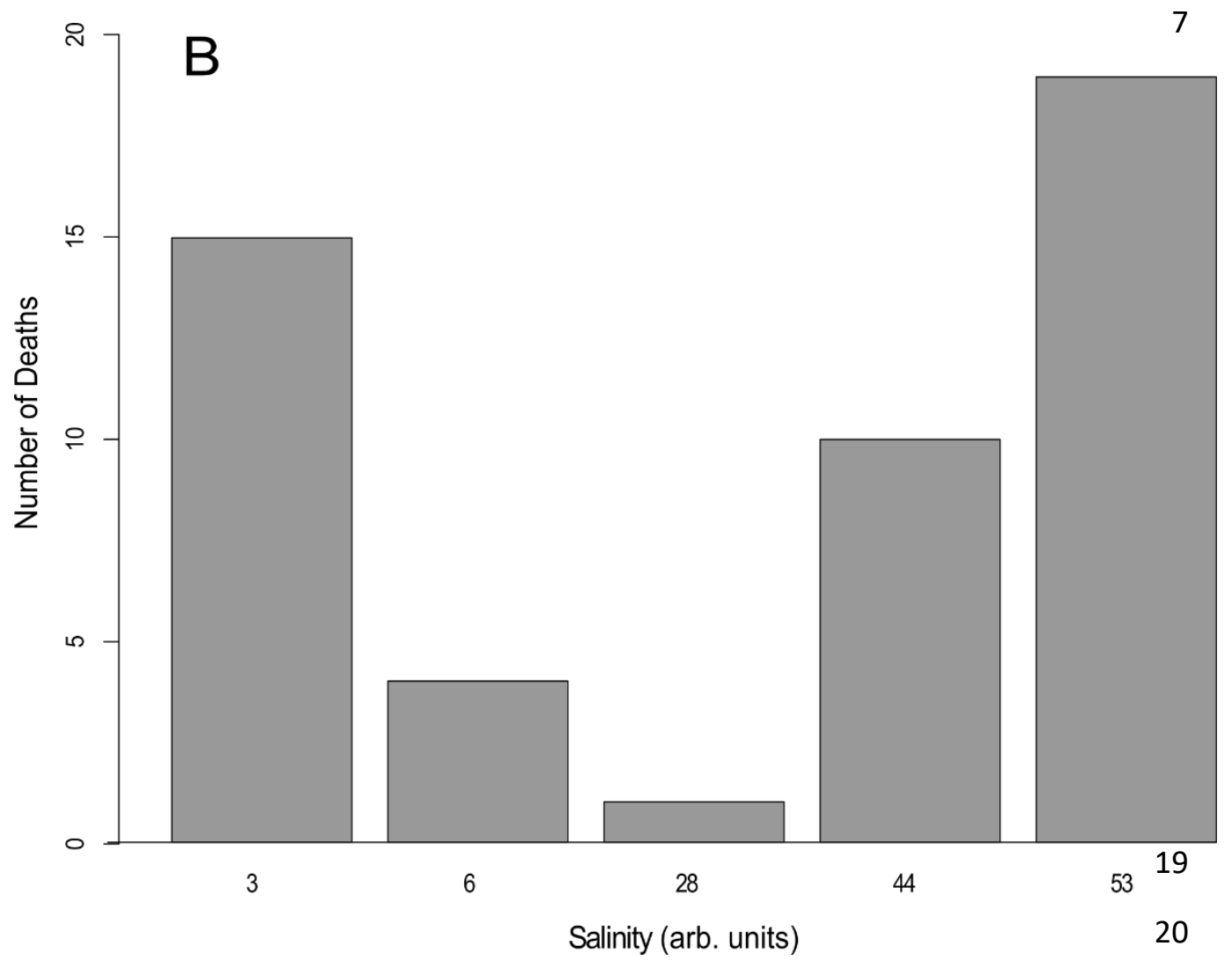

21

22

23 Clayton \& Spicer, Figure 2

24 
Physiological niche expansion
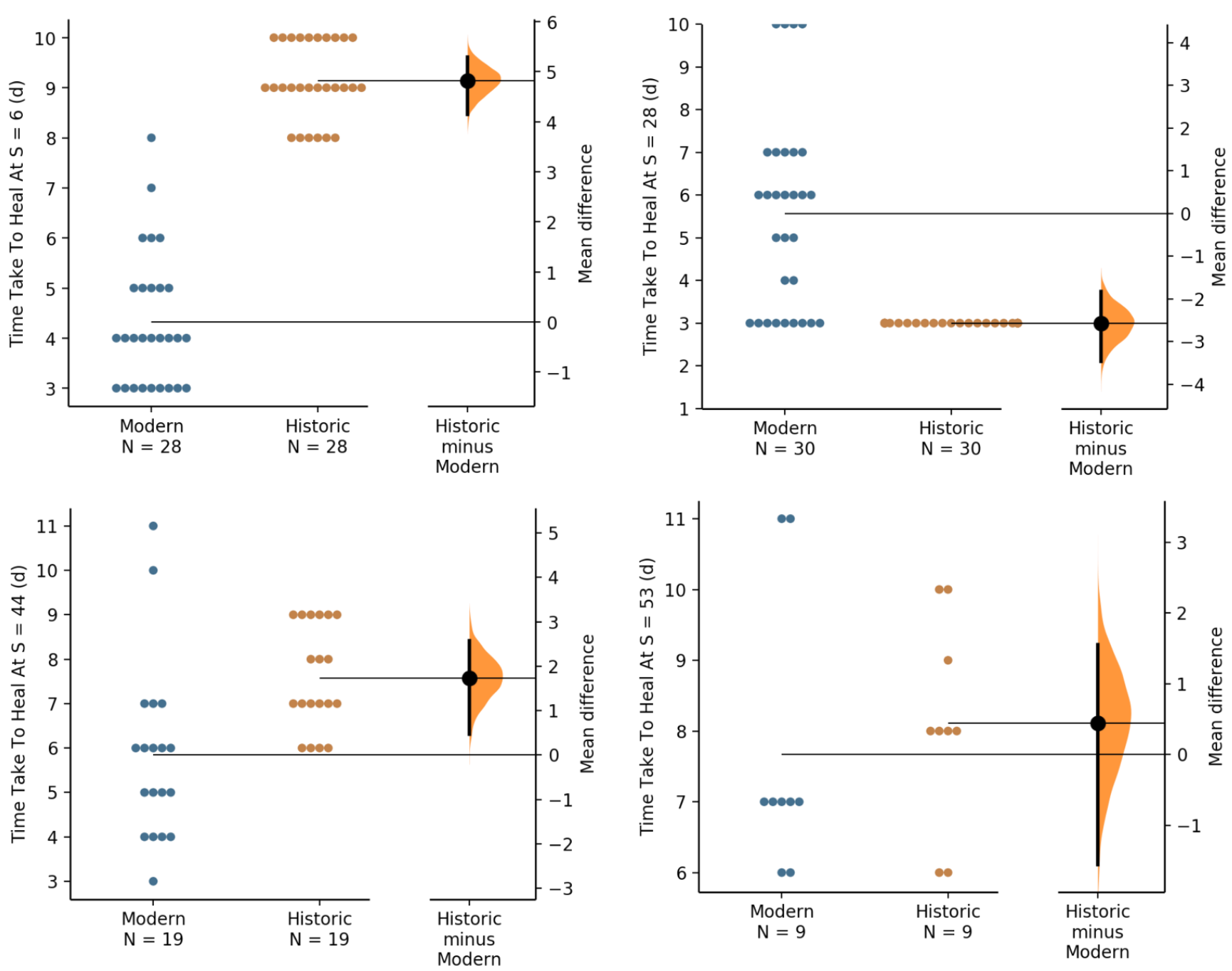

1 Clayton \& Spicer, Figure 3

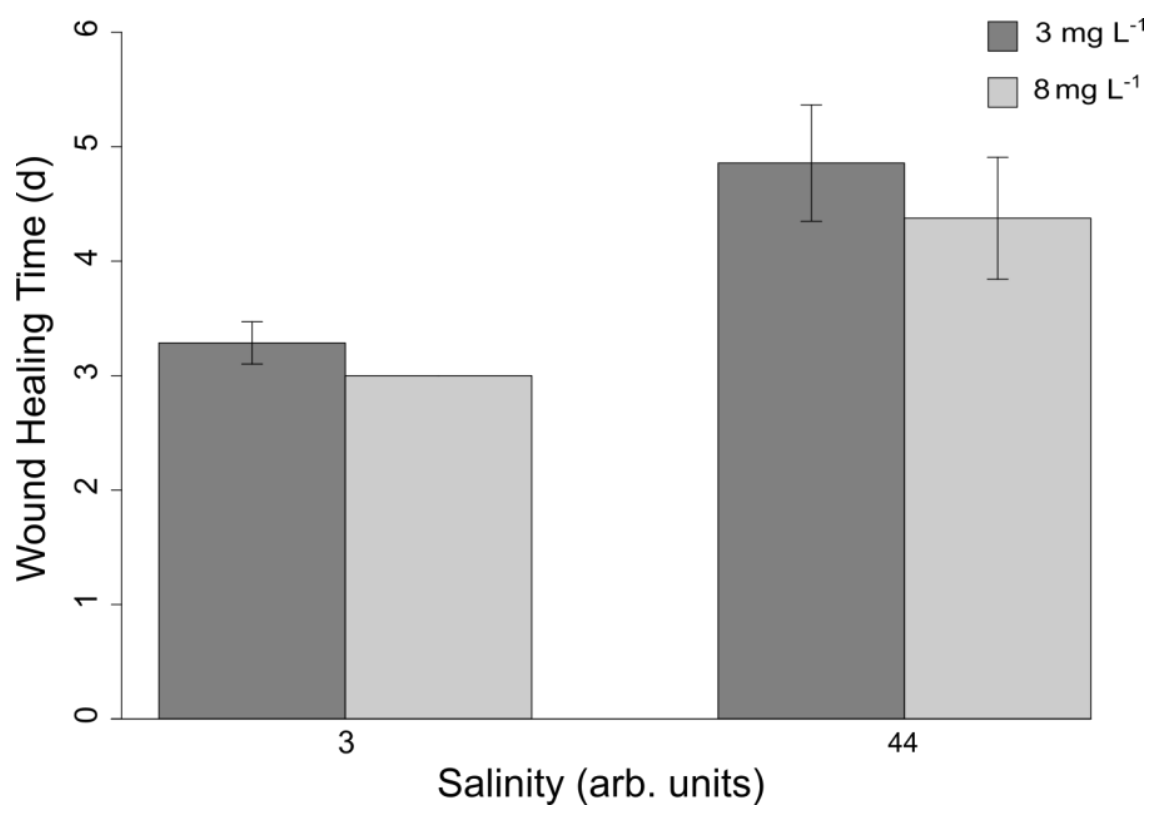


Physiological niche expansion

1 Clayton \& Spicer, Figure 4

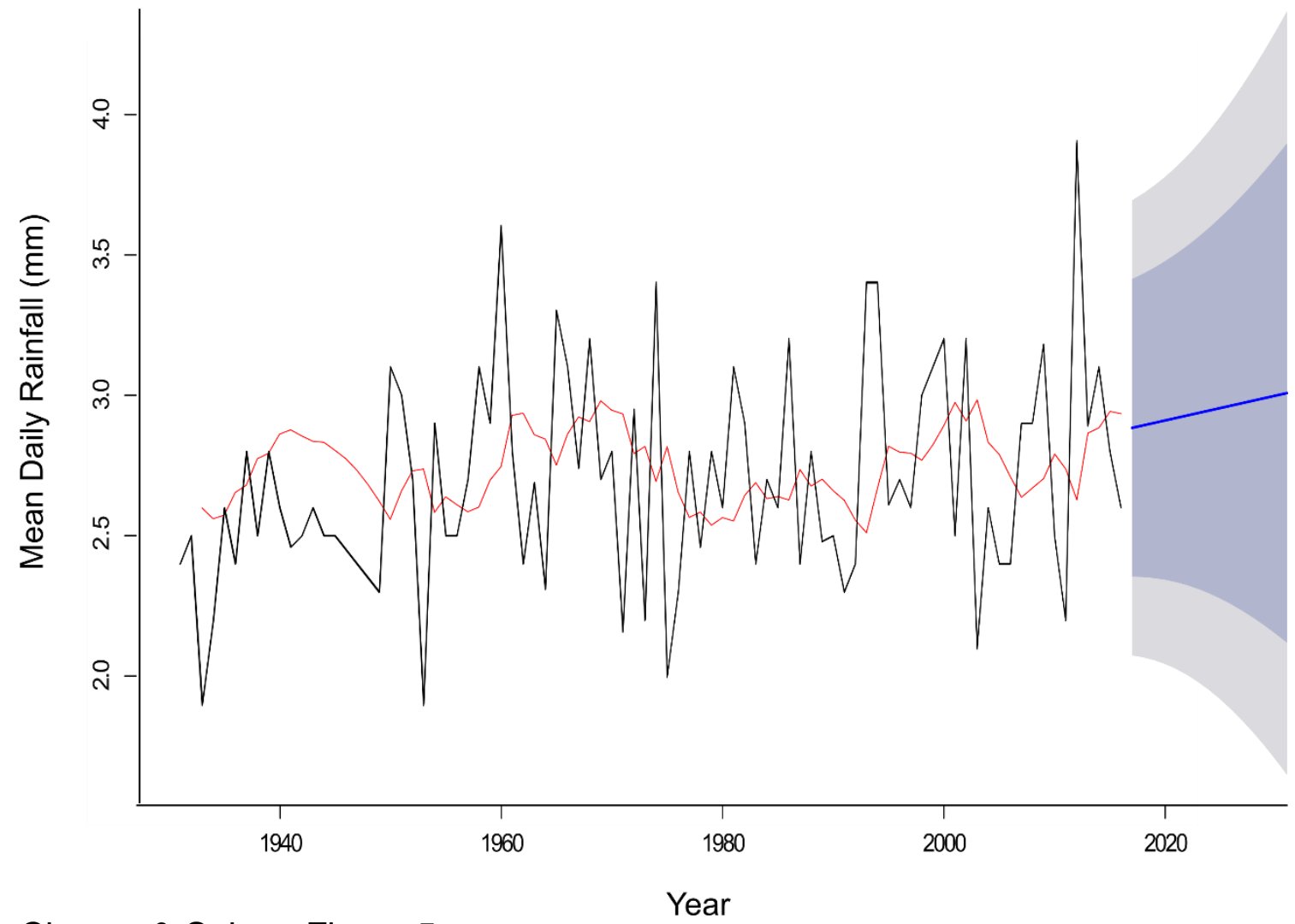

2 Clayton \& Spicer, Figure 5

3

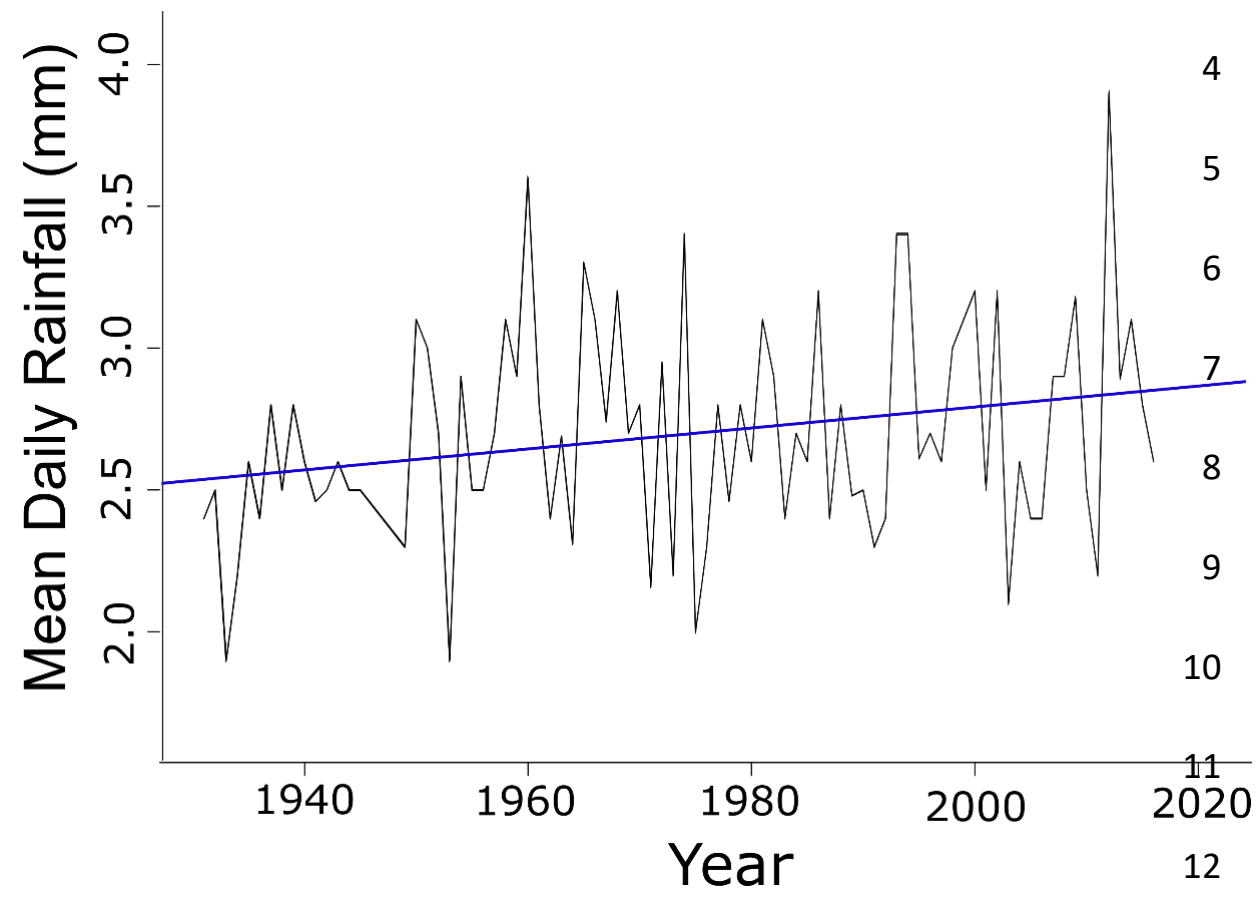


Physiological niche expansion

1 Clayton \& Spicer, Figure 6

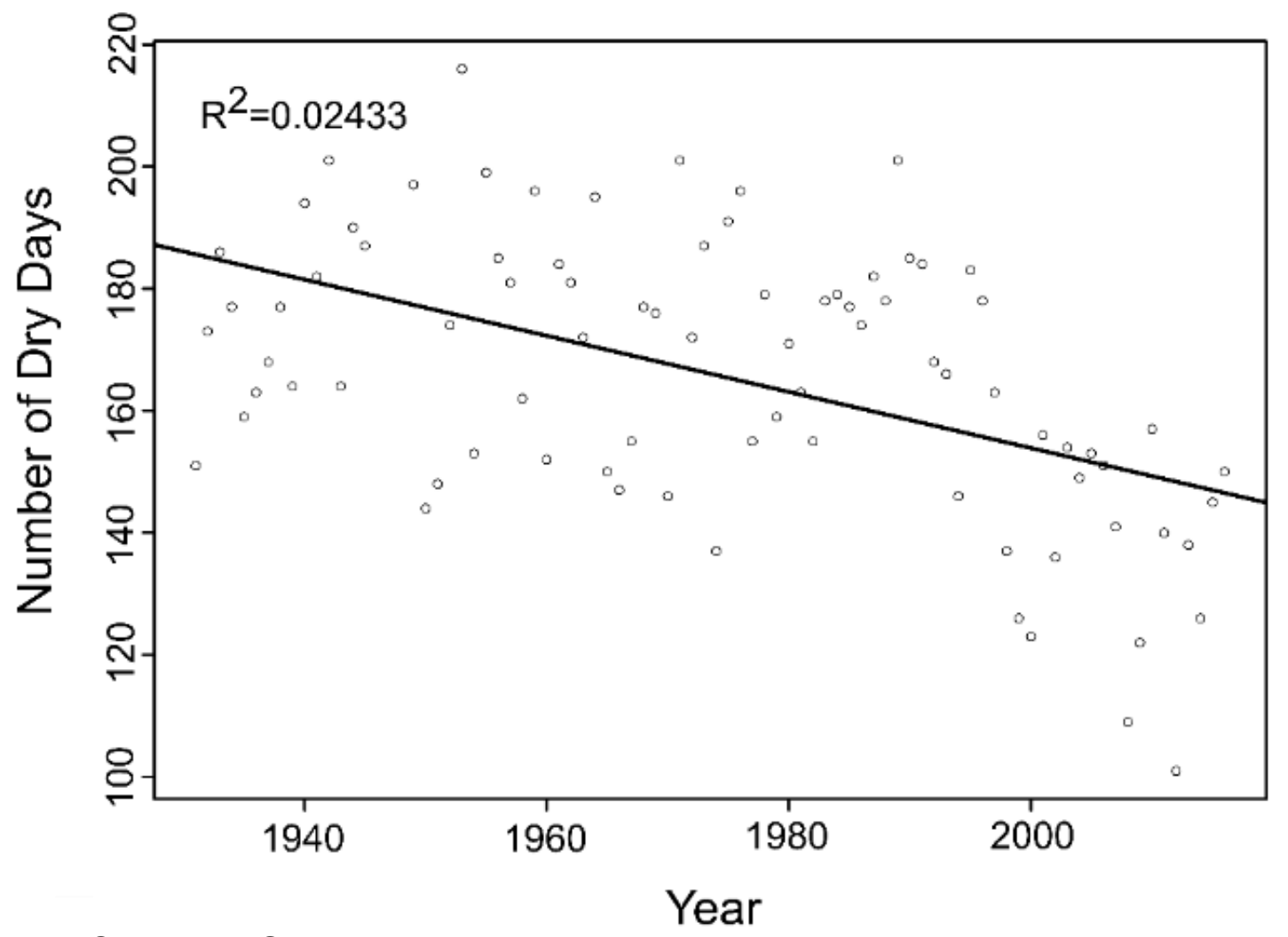

4 Clayton \& Spicer, Figure 7

5

6

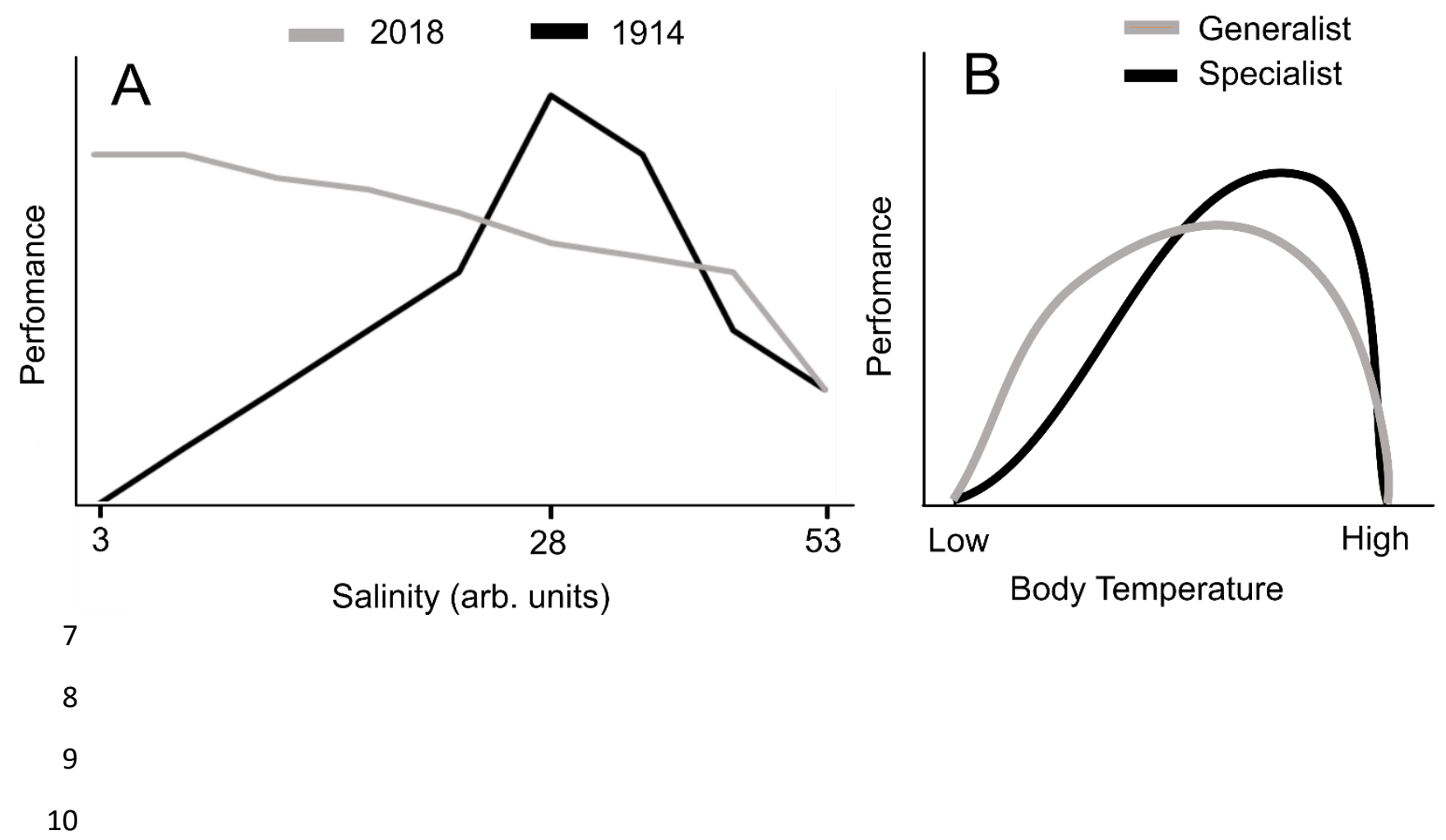


Physiological niche expansion

1

2

3

4

5

6

7

8

9 Clayton \& Spicer, Figure S1

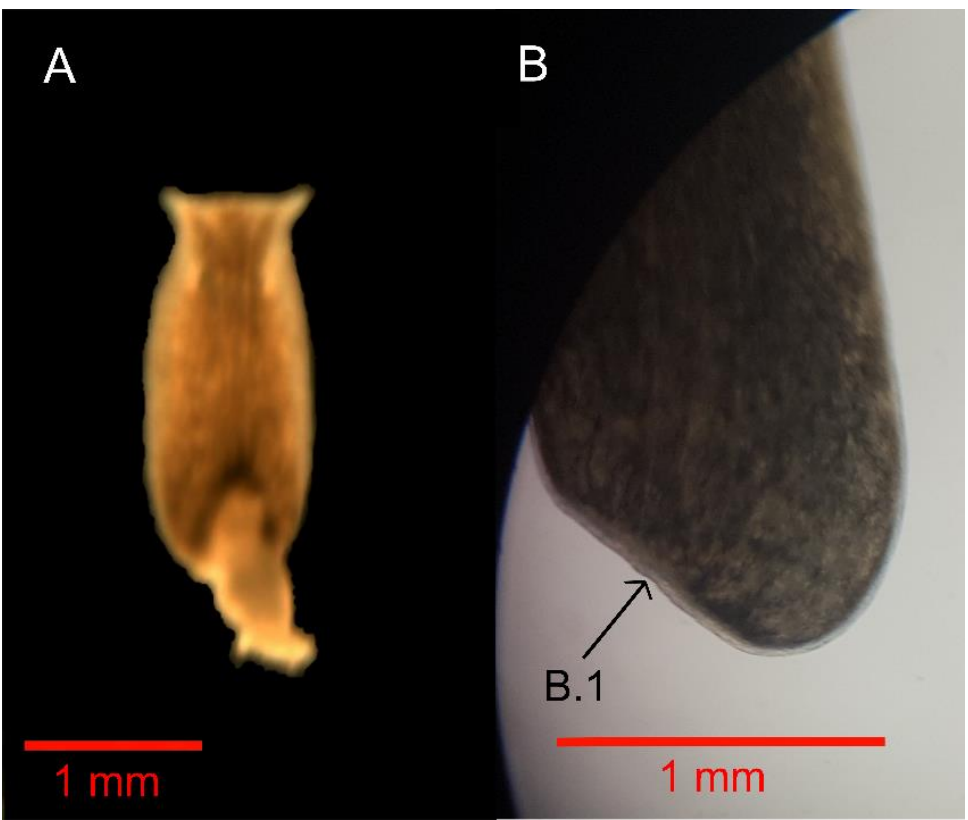

21

22

23

24

25

26

27 
Physiological niche expansion

1 Clayton \& Spicer, Figure S2
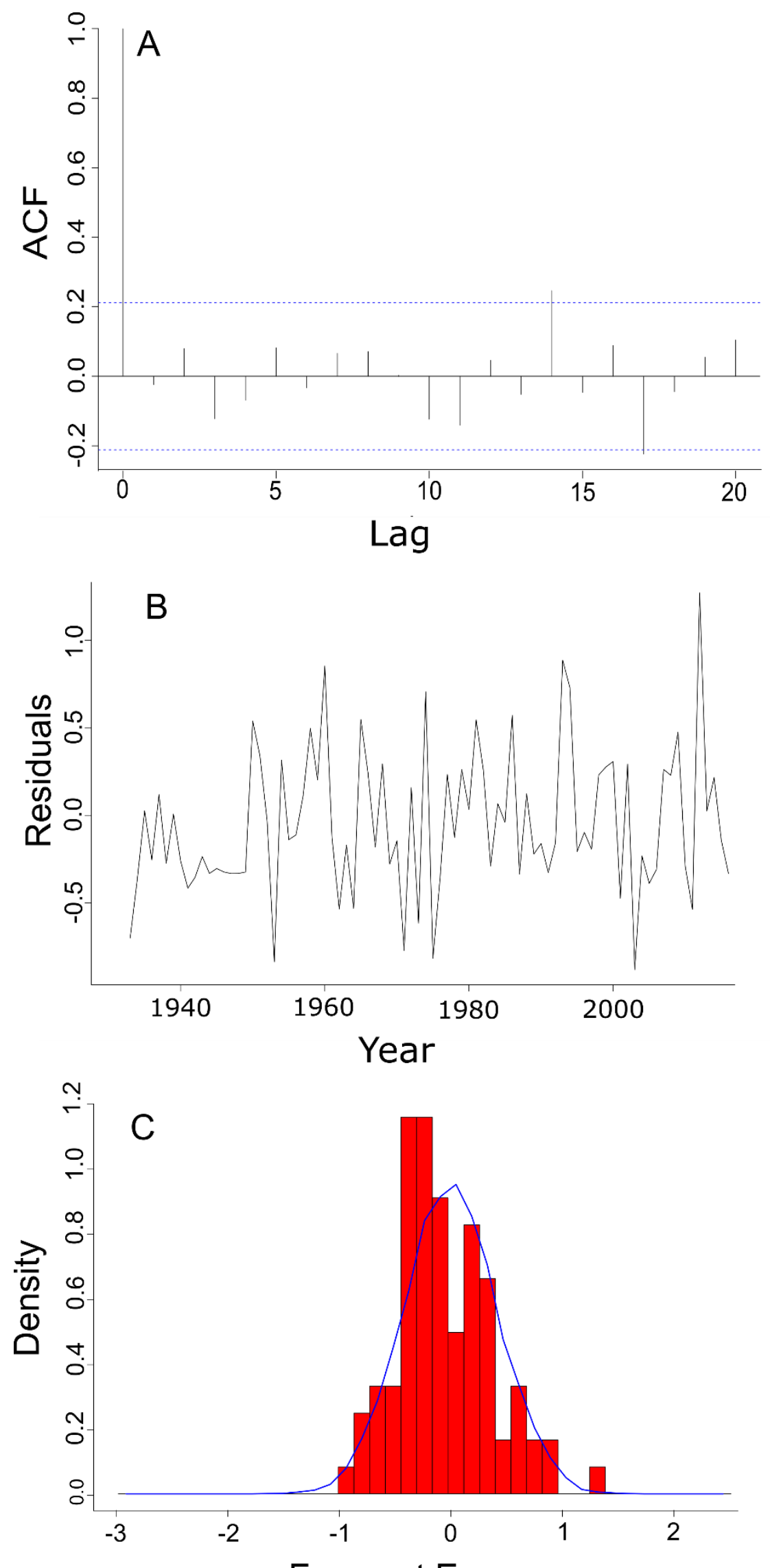

Forecast Errors 